ISSN 1112-9867

\title{
EXAMINATION OF FAULTS ACTIVE MOTION ON BURIED PIPELINES
}

\author{
Y. Parish \\ Assistant Professor and PhD in Civil Engineering - Research and Educational Complex in \\ Azerbaijan (Ministry of Energy) \\ University of Applied Science- East Azerbaijan Province
}

Published online: 15 May 2016

\begin{abstract}
During an earthquake, a buried pipeline may experience a severe loading as the result of the ground relatively large displacement along the pipe. Large ground movements may occur by faulting, liquefaction, lateral spreading, landslides and slope failures. Since the pipelines are widely spread, and in some areas necessarily cross through the areas with faults, therefore, improvement study of pipelines in areas with faults is very important. This article explores faults active motion on buried pipelines.
\end{abstract}

Keywords: water utilities; earthquake; vibrations; fault; pipe.

Author Correspondence, e-mail: yousefparish@yahoo.com

doi: http://dx.doi.org/10.4314/jfas.v8i3s.169

\section{INTRODUCTION}

Large deformations caused by the failure of slopes, earthquakes, faults move and pipe float in shallow trenches have created major damages in buried pipelines networks. Because of buried pipelines extensiveness in urban communities including in Tehran that have formed a confused skein, various factors causing failures in pipelines should be considered in the design of buried 
pipelines. Due to the longevity of underground pipelines and exploitation time in environmental conditions as well as regulations change, the need for improvements, retrofitting, preventative maintenances of these lines against destructive agents is critical. Fault motion is one of the destructive phenomena on the pipelines. In recent years, many researchers have studied effects of faults active motion on buried pipelines. Obviously, the usability of pipelines after the fault motion needs the capability of inelastic deformation without creating havoc.

The earthquake may cause serious damages to water utilities of a city. There are numerous statistics and reports about the severe damages caused by incidents on different utilities lifelines such as water, gas, electricity and telecommunications installations after the occurrence of a highintensity earthquake.

Such reports have been available since the 1906 earthquake in San Francisco, America. The earthquake seriously damaged water refinery and pipelines utilities which caused the lack of drinking water supply and multiple fires in the city after the earthquake. A separate study has reported the major earthquake of Mexico City in September 1985. The earthquake resulted in the lands wide displacement, damaged drinking water and wastewater treatment tanks and breaking main pipelines of the drinking water. As a result more than 4 million people lacked safe drinking water for three weeks.

In 1994 Northridge earthquake in California, drinking water utilities including treatment facilities and major pipelines of water transmission and distribution were broken due to the permanent destruction of land.

In 1995 Kobe earthquake in Japan, due to the land degradation and underground shake, more than 2,000 fractures, damaged pipes and drinking water utilities were reported in storage tanks and water distribution networks. Moreover, the earthquake effect on the sewers was in such a way that had led to the sewers protrusions across the region.

\section{THE EFFECTS OF UNEVEN GROUND MOVEMENT ON BURIED PIPELINES}

New pipelines, whether coastal or marine, are usually buried up in order that the reliance protection to be ensured. Buried pipelines are typically designed based on belt tension limits for internal pressure design. Especial tension analyses in terms of bending may be necessary for pipelines exposed to extreme temperature changes. In addition, the pipelines may need to design for external loads, for example, loads caused by heavy equipment on the ground. 
During the earthquake, a buried pipeline may experience a severe loading as a result of the relatively large displacement of the ground along the pipe. Large ground movements can be caused by faulting, liquefaction, lateral spreading, landslides and slope failures. However, in areas with high seismicity the movements caused by faulting and liquefaction such as lateral spreading can't be often avoided over the pipeline long distances.

Ground failure patterns associated with movements and caused by earthquakes are usually complex and show significant changes in displacement as a function of geological formations, soil type, and magnitude and earthquake duration.

The pipeline performance in the ground sustainable movement areas is closely depended on applying or non-applying of compressive or tensile deformations over pipelines. In fact, due to the existence of large fault displacements, a pipeline will be affected by bending and central deformations. Two deformations mode are possible when a buried pipeline is highly compressed. The pipeline may be isolated from the soil and buckled upward like an arrow or distorted locally and the wall may be shrunk.

Although the pipeline is relatively ductile in terms of stretch, the tension is likely caused by welding weaknesses, wall thickness, yield point heterogeneity and etc. For this reason, it is recommended to consider measures to limit the maximum tensile stresses by values which are significantly less than the ultimate capacity of the pipeline materials.

\section{GEOTECHNICAL INVESTIGATIONS}

Faulting is the main factor causing an earthquake. Faults are long extensions in which the earth classes and layers have been broken along these extensions and have generated a tape or Zone. These fractures are often steep and not vertical. Thus, in weight terms a plane rides over another plane. Faults place and extensions can be determined according to the tectonic map of the area. Earthquakes occur as a result of geodynamic movements of the Earth and its planes. By earthquakes one plane goes beneath another and the energy resulting from the displacement is released as seismic waves. Due to the linearity of some underground constructions, they may encounter with faults and even it is inevitable in some cases. Since the displacement caused by a fault is very malicious and structural designing in a way to show the strength in the face of these tensions is not affordable, in order to design and implement long underground constructions 
(tunnels, subways and...) it is most forcefully recommended that faults location and extensions to be considered and structures crossing with the faults extension to be avoided as far as possible.

The study of a fault displacement and movement can provide valuable information for engineers. This information could help to determine the fault movements rate (vertical and horizontal). Fault displacement varies with depth increase and even these movements are not the same along the fault.

To determine the displacement rate and the underground structure usage is important for structure designing and decision-making in the face of faults. The displacement, even a small one, will have a devastating effect on some structures and in contrast, such shifts on some other structures with different usages like channels are less important. Transmission pipelines should be located in a way that to be farm from the ground failures or to be placed and protected in a way that deformations resulting from the earth sustainable movements to be minimized.

A single or group of structures are often enclosed in a small area and in such cases the geotechnical program is designed so that to provide an accurate picture of the subsurface conditions. In contrast, transmission lines and distribution networks may cover a wide area so that to conduct a centered study will not be possible on the entire length of the line.

Since doing a detailed geotechnical studies is not feasible in a pipeline entire path, to ensure compliance of the current conditions in drilling the pipeline with design assumptions is very important.

For proper design of pipelines to resist against permanent deformation of land at the intersection of faults the designer must consider the specific information that is obtained from geotechnical studies. The information includes: The geometry of the fault (s), the extent of the fault zone, the type, amount and direction of movement which suddenly occurs during an earthquake or gradually over the long term (creep) and recurrence time interval for a given amount of displacement. Perhaps, the amount and type of surface displacement are the most important factors that should be considered in seismic design of pipelines at the intersection of active faults. The amount of the fault surface displacement is perfectly associated with the size of the earthquake (magnitude and length of the fault rupture). Other factors such as the type of fault movement (strike-slip, normal, etc.) and tectonic setting seem partly impact the amount of surface displacement but the available data to determine their significance is not enough. 


\section{FACTORS AFFECTING THE PIPELINE PERFORMANCE AT THE INTERSECTION OF THE FAULT}

Factors affecting considerably the pipeline performance exposed to the fault movements consist of: Burial depth, the moat shape, the amount of the fault relative displacement, intersection angle of the pipeline with the fault, soil properties and effective uninhibited lengths. The pipeline performance is also affected by materials properties, the pipeline geometry and its internal pressure. Generally, the pipeline dynamic response as compared to the deformation caused by faulting is small and can be ignored so that good results can be obtained from an applied relative static displacement.

Other factors impacting the pipeline performance includes the pipeline diameter and the wall thickness, the internal pressure and pipes material properties. Among these, the wall thickness at the intersections leading to the tension is the main factor. Longitudinal forces acting on the pipeline from the surrounding soil are proportional to the diameter of the pipe while the pipeline resistance against the forces is proportional to the product of the diameter of the pipeline in the thickness.

The ratio of the exerted longitudinal force to the pipeline resistance determines the pipeline effective inhibitory length. Thus, this length is directly proportional to the thickness of the pipe wall. As a result, the fault intersection capability is independent of the pipeline diameter and in direct contact with the pipe wall thickness. Increased pipeline wall results in decreasing the tensile stress at the fault intersection whereas other factors remain unchanged.

For pipelines which are subject to lateral earth pressure, an oval ring contraction is possible, unless a high limit of the ratio of pipeline diameter to the wall thickness to be applied.

The internal pressure in addition to reducing oval ring contraction improves the pipeline resistance against the local wrinkling by reducing volatility impacts of the initial geometric defects.

\section{BURIED PIPELINES IN DEALING WITH FAULTS}

An earthquake makes a lot of damages to buried pipeline systems. These damages cause many problems in daily life. Since the pipelines are widely spread and in some areas necessarily cross thorough the areas with the fault, pipelines improvement study in areas with faults is very 
important. Loading caused by an earthquake is exerted as the fault displacement; as a result, the displacement causes force and tension in the buried pipeline.

Buried pipeline failure is in the form of a failure caused by the interaction of central force and bending moment. The design parameters sensitivity for the failure of the pipeline has been examined. The results show that with the increase of the fault displacement, the pipeline diameter, the pipe depth burial as well as the friction angle between the soil and pipe, it becomes closer to the breakdown region.

However, pipes studies showed that as the fault movement is larger, length of the pipe deformed part will be longer. Therefore, the deformable zone should be considered larger and in the case of using flexible joints or rails along the lines, amount of the displacement should be considered further.

\section{SUGGESTIONS FOR FURTHER UNDERSTANDING OF THE CRITICAL POINTS}

- Ultrasonic tests for pipes wall thickness measurement to evaluate the effects of corrosion of the pipes used in the earth depth, places with difficult access, height, roofs adjacent or inside the ceilings.

- Radiology and radiography (RT): To check device status and fluid transfer equipment located along pipelines; such as pumps, compressors and etc.

- To evaluate the pillars, controller frames, pipes and steel braces structures which includes to test and check welds safety and quality through non-destructive testing (NDT) and Ultrasonic testing (UT), penetrant liquids testing (MT) and magnetic particle testing.

Among the strategies to cope with earthquake in pipelines crossing faults, the layout change, profile change, structural measures, systematic measures and the layout change in accordance with the amount of the fault movement can be noted. These strategies are divided into two categories of hardware strategies and software strategies which are described as follows:

- Hardware strategies: Hardware strategies involve structural measures and strategies based on the design change. By adopting this strategy, even after the earthquake, continued operation of the pipeline is possible. The fault displacement at a small to medium scale is covered by these measures.

- Software strategies: software strategies involve the change in the basic idea and systematic measures. The fault displacement with a value at a medium to large scale, can't be adapted to the 
mentioned hardware mentioned measures, is covered by these measures. Damages are partly unavoidable through software strategies. These measures are done to maintain the performance or minimize the loss of function.

- To check the materials used.

- To check the connections, splits and their resistance.

\section{ANALYSIS OF PIPELINES UNDER THE FAULT MOVEMENT}

The most common method to tolerate the fault motion for the welded steel pipelines is to use the pipe deformation capability in the inelastic range in stretch for coordinating with the ground deformation without any rapture.

Whenever possible, the pipeline at the intersection of the fault line should be located in a way that the pipeline to be affected by tension with a little bending. Locating the pipeline in a way to comress it should be avoided because the pipeline ability to tolerate pressure tensions without rapture is much less than the tensile stresses.

There are several methods for the analysis of buried pipelines at faulting. Through the necessary reforms in constraints, these methods can be used for buried pipelines and the similar cases. These methods include:

1) Newmark-Hall's method

2) Kennedy et al method

3) Finite Element Method

The first two methods assume the fault motion as it occurs in a defined single plane and consider soil aggregates on both sides of the fault as two moving rigid objects.

Newmark-Hall method provides a lower bound estimate of the pipeline tension since it assumes that the pipeline is able to be separated from the ground; as a result, any side constraint. Then, the pipeline id deformed as a direct line between two inhibitory points. On the other hand, Kennedy et al. method leads to the higher bound estimate of the tension since by assuming that the pipeline has not flexural stiffness overestimates the flexural stiffness.

Displacements caused by the fault motion are naturally three-dimensional and contain faults depending on the extension slip and normal slip components. Therefore, inhibitory points movements of the pipeline is dependent on the pipeline locating compared to the upper surface of the fault and the fault plane deviation compared to the upper surface. 
During the faulting and taking into account the main parameters affecting the issue, a pipeline system is usually spread over a large area and this feature exposes the system to the additional risks compared to other utilities which occupy a small area. These parameters include:

A) To surrender the pipe under the central and bending load slip through plastic hinges and a central slip

B) Longitudinal friction at the interface between the pipe and soil.

C) Lateral resistance of the soil

Seismic analysis of the buried pipelines exposing to faulting is a major task including a complex interaction issue of soil - structure with many numerical problems such as:

1) Three-dimensional geometry

2) Large deformations

3) Local buckling of the cross section

4) Eulerian buckling under the faulting pressure

5) The pipe slip due to the soil around

6) Non-linear behavior of the soil.

\section{DESIGNING PIPELINES TO PASS THROUGH THE FAULT}

In designing pipelines to pass through the fault, the following considerations usually improve the pipeline capacity to resist against the fault heterogeneous motions:

- Where there is a practice, the pipeline intersection angle relative to the extension slip fault should be selected in a way that the pipeline to be placed under tension.

- For reducing the frictional resistance, depth of buried pipelines in fault zones to be minimal as much as possible. If there is no threat to the surface, the pipe should be buried in the ground surface

- Increasing the wall thickness of the pipe, will enhance the pipeline capacity to move the fault in a given level provided that a relatively thick pipe to be used on either side of the fault.

$>$ Precise control of the embankment around the pipe is required for distances close to the fault. Generally, a loose to semi-dense granular soil without coarse lumps or gravel is suitable for embankment.

Insertion the pipeline on the embankment built with low frictional resistance. 
To insert the pipeline in trenches larger than the necessary limit and to fill them with resistant and appropriate materials.

To reduce the friction, the used surface to be flat as much as possible and the used coverage to be flat and stiff like fiberglass or epoxy.

$>$ In the fault place it is better that the pipeline to be direct and without curve and burial depth not to be changed and as much as possible the pipeline to be close to the fault and without any elbows, tees, flanges and similar constraints.

\section{DISCUSSION AND CONCLUSION}

Although the pipeline was relatively ductile in stretch, the tension is likely caused by welding weaknesses, the wall thickness changes, the yield point heterogeneity and etc. For this reason, considering measures to limit the maximum tensile stresses to values which are significantly less than the ultimate capacity of the pipeline materials is recommended.

Since the displacement caused by a fault is very malicious and structural designing in a way to show the strength in the face of these tensions is not affordable, in order to design and implement long underground constructions (tunnels, subways and...) it is most forcefully recommended that faults location and extensions to be considered and structures crossing with the faults extension to be avoided as far as possible.

The study of a fault displacement and movement can provide valuable information for engineers. This information could help to determine the fault movement rate (vertical and horizontal). Fault displacement varies with depth increase and even these movements are not the same along the fault.

Transmission pipelines should be located in a way that to be farm from the ground failures or to be placed and protected in a way that deformations resulting from the earth sustainable movements to be minimized.

The amount of the fault surface displacement is perfectly associated with the size of the earthquake (magnitude and length of the fault rupture).

Generally, the pipeline dynamic response as compared to the deformation caused by faulting is small and can be ignored so that good results can be obtained from an applied relative static displacement. 
The fault intersection capability is independent of the pipeline diameter and in direct contact with the pipe wall thickness. Increased pipeline wall results in decreasing the tensile stress at the fault intersection whereas other factors remain unchanged.

In the event that to avoid the collision of the structure with the fault is not possible, it is suggested that the following points to be considered in structural design:

- To use flexible connectors in the place of the structure collision with the fault

- To use intentional loopholes for focusing damages an earthquake

- To increase the cross-section by the size of the expected displacement from an earthquake The most common method to tolerate the fault motion for the welded steel pipelines is to use the pipe deformation capability in the inelastic range in stretch for coordinating with the ground deformation without any rapture.

\section{REFERENCES}

[1] Dabbaghi, M., Plumbing installations retrofit, 2006, the first International Conference on Seismic Retrofit

[2] Rajai, H, evaluation of pipelines behavior against fault movement, the first International Conference on Seismic Retrofit

[3] Komakpanah, A, Montazerghaem, S, International Institute of Seismology and Earthquake Engineering, Proceedings of the First Workshop on examining strategies for reducing earthquake damages in Iran, Tehran, 1994.

[4] Earthquake damage and countermeasure of industrial lifeline andequipment, Yonglu Li \& Xiangdong Xi.

[5] Earthquakes and Seismic Faulting: Effects on Tunnels , VILLY A. KONTOGIANNI \& STATHIS C. STIROS.

[6] Joe Nane (joe)Wang ., June 1993.

[7] Kiezo Ohtomo, Toshio Shiero, Tadashi Kawai ,Kensye Kanaya , Experimental aspect of laminar shear sand box excitation test whit embedded RC model.

[8] seismic behavior of underground structures and site response, Y.M.A.Hashash. 
How to cite this article:

Parish Y. Examination of faults active motion on buried pipelines. J. Fundam. Appl. Sci., 2016, 8(3S), 105-115. 